\title{
In Situ TEM Study of the Annealing of Titania Nanotubes for Use as Novel Electrochemistry Based Water Purification Devices
}

\author{
Brian Van Devener, Hammad Malik, Swomitra Mohanty and Krista Carlson \\ University of Utah, Salt Lake City, Utah, United States
}

Access to clean, potable water is a significant world-wide problem. Approximately 1-2 billion people lack a safe source of drinking water according to the World Health Organization, with E. coli as one of the primary bacterial contaminants. Recently, Beeman, et al. described a novel, point-of-use, electrochemically-based purification device, which consisted of defect laden titania nanotubes on a titania support [1]. In aqueous media, the electrocatalytic production of radical species on the surface of defect rich $\mathrm{TiO}_{2}$ nanotubes was found to initiate cellular death in waterborne pathogens such as E. coli [2,3]. The titania nanotube arrays are synthesized anodically on titanium supports and are initially produced as amorphous structures. Amorphous $\mathrm{TiO}_{2}$ nanotubes are electrical insulators and reductive annealing is required to create a defect rich polycrystalline structure in the nanotubes which has the necessary conductivity to operate as electrochemical devices. Reductive annealing in a $2 \% \mathrm{H}_{2}$ (balance $\mathrm{N}_{2}$ ) at $500^{\circ}$ $\mathrm{C}$ has been shown to produce an optimal number of defects in anatase phase crystallites within the nanotubes [4]. To date, this transformation has not been studied under real-time reaction conditions. This study presents the first in situ TEM study of the annealing of titania nanotubes in a reductive atmosphere. Utilizing a Protochips, Inc., Atmosphere 200 gas cell device, we performed in situ TEM on $\mathrm{TiO}_{2}$ nanotubes dispersed on Atmosphere E-chips. A JEOL JEM-2800 FEG S/TEM operated at $200 \mathrm{kV}$ was used for imaging. Annealing was performed while flowing a $2 \% \mathrm{H}_{2}$ (balance $\mathrm{N}_{2}$ ) gas mixture with a nominal pressure of 100 Torr held throughout the experiment. The temperature was ramped from room temperature up to $1000^{\circ} \mathrm{C}$, stopping at several temperatures for imaging and holding at critical points. Figure 1 shows four different images of a cluster of $\mathrm{TiO}_{2}$ nanotubes taken at key temperatures. At $300^{\circ} \mathrm{C}$ (a), the structure is initially amorphous, as can be seen from the lack of any diffraction contrast in the image. After holding at $300^{\circ} \mathrm{C}$ for approximately 5 minutes, the onset of crystallization can be seen (b). The wall structure of the nanotubes can be seen to be defined by numerous crystallites of anatase phase $\mathrm{TiO}_{2}$. Above $300^{\circ} \mathrm{C}$, electron transfer from hydrogen molecules to oxygen in the $\mathrm{TiO}_{2}$ lattice leads to oxygen atom abstraction, and vacancies in the lattice [5]. The promotion of oxygen vacancies and other structural defects lowers the resistivity of the $\mathrm{TiO}_{2}$ through the creation of delocalized electrons [6]. Heating to $500^{\circ} \mathrm{C}$ shows continued production of defects within the now crystalline structure (c). Further heating to $600^{\circ} \mathrm{C}(\mathrm{d})$ and higher temperatures, promotes the production of additional defects as well as rutile phase crystallites and sub-stoichiometric phases of titania known as Magneli phases. The in situ TEM results will be presented in the context of earlier work, which looked at the change in density of states (DOS) and electronic band structure of titania phases during annealing treatment using density functional theory (DFT) [4]. Additional considerations will be discussed regarding the differences in the nucleation of crystallites and phase changes in single nanotubes vs. clusters of nanotubes. The role of the titania support in promoting structural changes in the nanotubes during higher temperature annealing will also be presented, as well as the degradation of nanotube morphology [7, 8]. 


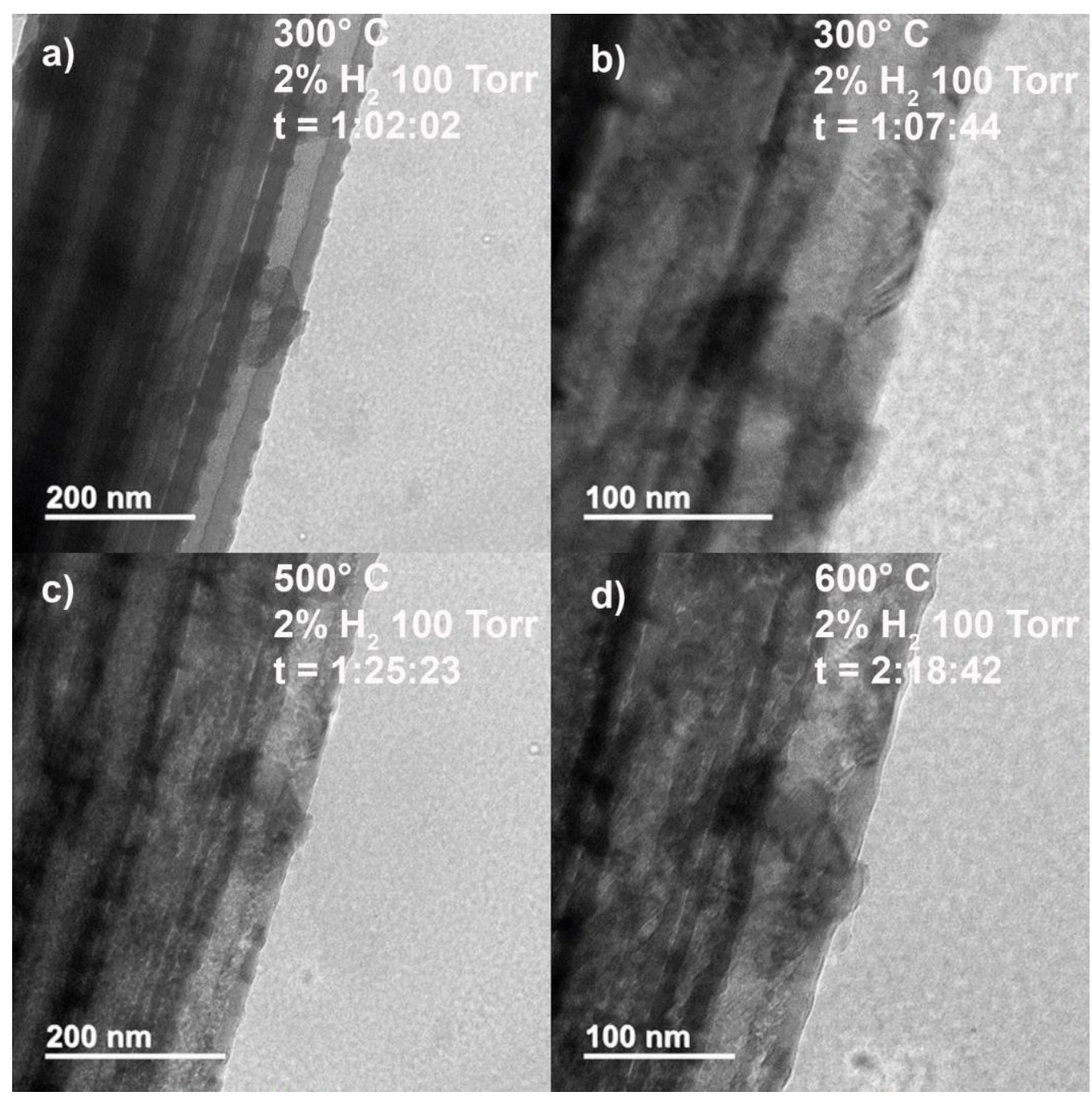

Figure 1. In situ annealing in $2 \% \mathrm{H}_{2}$ (balance $\mathrm{N} 2$ ) of $\mathrm{TiO}_{2}$ nanotube cluster. (a) Amorphous (as produced) nanotubes at $300^{\circ} \mathrm{C}$. (b) Onset of crystallization at $300^{\circ} \mathrm{C}$ after $\sim 5$ min hold. (c) Continued production of crystallites and defects at $500^{\circ} \mathrm{C}$. (d) Additional defect production at elevated temperature, $600^{\circ} \mathrm{C}$.

\section{References}

[1] M Beeman et al., Sensors 18(5) (2018), p. 1497

[2] J Huber et al., Journal of Environmental Science 44 (2016), p. 38

[3] Carlson et al., Journal of The Electrochemical Society 163 (2016), p. 395

[4] H Malik et al., Scientific Reports Submitted.

[5] H Liu et al., Chemosphere $\mathbf{5 0}$ (2003), p. 39

[6] O Johnson, Applied Physics Letters 13 (1968), p. 338

[7] This work made use of University of Utah USTAR shared facilities supported, in part, by the MRSEC Program of the NSF under Award Number DMR-1121252.

[8] This study was made possible by the support of the United States Government and the American people through the United States Agency for International Development (USAID). The contents are the sole responsibility of the University of Utah and do not necessarily reflect the views of USAID or the United States Government. 